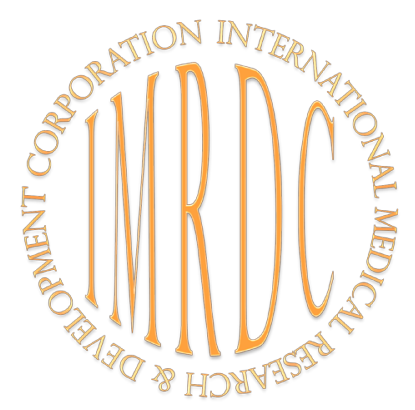

\title{
A Mentally Ill Patient and his/her Social Environment
}

\author{
Mikhail A. Nekrasov, MD, ScD* \\ Orel State University, Orel, Russian Federation
}

\begin{abstract}
Background: Mental illness (MI) markedly affects a person's daily living and leads to disability, reduced duration of active life and, finally, tremendous economic losses incurred by the state and society. Moreover, it has an adverse impact on the patient's immediate social surroundings. The aim of the research was to study various aspects of mentally ill patients' daily living and their social environment in order to optimize psychosocial rehabilitation programs and therapies.

Methods: One thousand forty two mentally ill people and 580 persons from their social environment participated in an anonymous social survey. The survey was carried out using specially developed structured questionnaires.

The results showed that MI changes the quality of life of mentally ill people (MIP): impaired well-being (84.4\%), curbing of interests (36.0\%), increased emotional sensitivity (39.0\%), low self-esteem $(75.4 \%)$, problems in family relations $(78.0 \%)$, dramatic loss of sexual activity $(72.3 \%)$, and in $75.8 \%$ patients - stigmatizing effect of their MI. The presence of a mentally-ill member in a family significantly affected the life and inner world of people close to that member, and modified their professional activity $(38.8 \%)$, daily living $(56.8 \%)$ and emotional state $(36.2 \%)$.

Conclusion: To improve application of psychosocial rehabilitation methods, an attempt was made to conduct a comprehensive medical and social study of the mentally ill and their social environment.
\end{abstract}

Keywords: mentally ill patient; relatives of a mentally ill patient; the quality of life; psychosocial rehabilitation methods.

\section{Introduction}

It is common knowledge that mental illness (MI) has a marked impact on a person's daily living and modifies his/her social status [1-3], possibilities for interpersonal communication [4,5], family relations [6], thus leading to a decrease of physical activity and confidence in his/her abilities [7]. The above-mentioned changes are facilitated by the formation of cognitive deficiency $[7,8]$ and the negative influence of the social environment, which often results in development of stigmatization (and self-stigmatization) $[9,10]$, distorting, in many cases, the patient's interaction with official psychiatric services [11]. At the same time, living together with a relative suffering from a psychiatric disorder leads to modification, whether of positive or negative character [13], of the structure of intra-familial relations [12]; and the effectiveness of preventing MI relapses is largely associated with the effectiveness of cooperation among psychiatric specialists, patients and patients' relatives [14].

The aim of the research was to study various aspects of mentally ill patients' daily living and their social environment

*Corresponding author: Prof. Mikhail A. Nekrasov, MD, ScD. Orel State University, Orel, Russian Federation.

E-mail:nekrasovma77@ya.ru in order to optimize psychosocial rehabilitation programs and therapies.

\section{Methods}

The research was carried out as a survey in Orel regional psychiatric hospital and Orel regional psycho-neurological dispensary. After the informed consents for participation in the experiment were obtained, 1042 mentally ill patients who were receiving in-patient and out-patient treatment, as well as 580 relatives of such patients, responded to questions. The survey was carried out using specially developed structured questionnaires. Patients were randomly selected for the survey. A questionnaire for the patients contained 102 questions divided into six thematic sections: (a) socio-demographic characteristics, (b) information about the disease and its treatment, (c) features of psychopharmacological therapy, (d) impact of MI on the various aspects of the patient's life, (e) assessment of medical activity and mental health service in the region, and (f) degree of patient satisfaction with quality of medical care. A questionnaire assessing the opinions of the relatives of patients consisted of 51 questions, which included four sections of information: (a) general information (passport data, occupation, a relationship with the person with MI, the duration of the illness, the presence of disability, 
etc.), (b) information about the MI of the relative and the history of treatment (hospitalizations, the interval between them, the duration of treatment, information on prescribed drugs), (c) impact of MI of the relative on the respondent's life (professional work, personal life, emotional state, the occurrence of limitations in daily life), and (d) assessment of mental health service and therapy for the sick relative (accessibility, effectiveness, quality, complexity of treatment, etc.). Specially instructed employees of psychiatric facilities controlled respondents' completion of questionnaires. Some questions in the questionnaires for the patients and their relatives were identical. Results were statistically processed using the software packages Statistica 7.0 and Biostat. The mean + SEM were calculated. A value of $\mathrm{P}<0.05$ was considered statistically significant.

\section{Results}

Among the patients with MI, the percentages of men and women were nearly the same: $47.8 \%$ and $52.2 \%$, respectively, with the dominating age group of $21-45$ years. Among the participating relatives of the patients, the percentage of women was prevailing $-78.3 \%$ and $60 \%$ of them were over 45 years old and most were mothers $(57.5 \%)$ of the patients or their wives (23.6\%) (Fig.1).

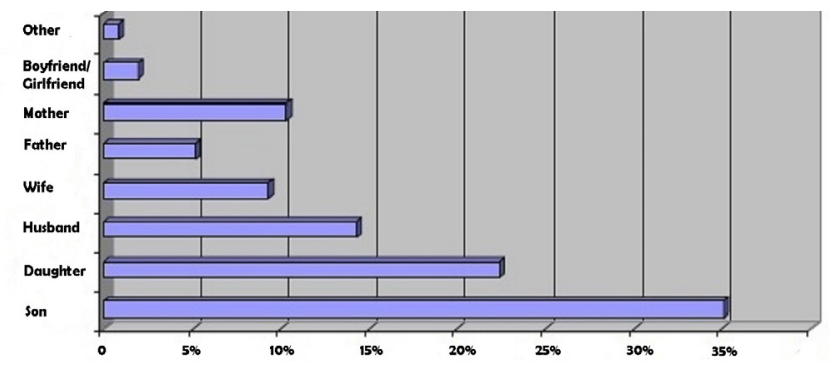

Fig. 1. Relationship of the respondents to the mentally ill.

Based on information obtained from both questionnaires, duration of MI in the patients was over 10 years; moreover, one-third of the patients (37.2\%) were diagnosed with a psychic disorder before the age of 20. In men, the illness manifested for the first time at the earlier age than in women $(\mathrm{P}<0.001)$. Over $70 \%$ of the patients had a disability status. Duration of MI and severity of disability were revealed to be in a direct relation. Over two-thirds of the patients $(80 \%)$ had experienced treatment at psychiatric facilities, and $37.2 \%$ of the patients had to receive treatment against their will. The survey results testify to the poor educational background of the patients. Patients with primary education accounted for $27.2 \%$; secondary (vocational), $67.3 \%$; and with higher education, only $5.5 \%$. Analysis of social status of the patients showed a direct relation between their educational background and their social status. The largest category was working people (33.7\%): farmers accounted for $25.1 \%$; office workers, $20.0 \%$; and students, less than $1 \%$.

An important characteristic of the mentally ill population under study was their labor status. At the moment of survey, only $15.9 \%$ had a stable salaried job, and only $12.5 \%$ preserved their professional level whilst the majority worked in jobs requiring a lower qualification. Many patients were found to have a negative career history with frequent changes of employment caused by conflicts with the management and colleagues, impaired ability to work and, in some cases, for psychopathological reasons. One in six patients $(16.7 \%)$ reported numerous changes of employment (from 3 to 5 times or more). Apparently, these were the causes of patients' dissatisfaction with their financial situation (67.9\%). Considering that the majority of patients $(77.4 \%)$ were of working age, the obtained results may prove the presence of marked labor disadaptation and ineffective socialization of the population under study.

The impact of MI on the general feeling of the respondents was assessed in the course of research. The overwhelming majority of patients $(84.4 \%)$ reported feeling unwell, with $17.4 \%$ reporting significant impairment of their well-being. Moreover, the extent of adverse impact that MI has on a patient's well-being is directly proportional to his/ her age and to number and frequency of stays in psychiatric facilities.

It is worth giving individual consideration to the impact of MI on the emotional aspects of human life. Changes in their emotionality was reported by $83.9 \%$ of patients, which primarily manifested as curbing of interests; $55.2 \%$ of patients reported on such disorders. They showed increased sensitivity or even tenderness toward outer influences $(39.0 \%)$ or, vice versa, absolute indifference to all things around them $(9.0 \%)$. For this reason, a large share of patients $(54.7 \%)$ did not visit, for long time, any places of recreation, museums, exhibitions, cinemas, etc.

Nearly one-third $(30.8 \%)$ of the respondents reported on their becoming very passive, and one-tenth $(10.1 \%)$ of them had no desire to do anything. The researchers noted that a significant part of such patients sought help from psychologists and psychotherapists help; i.e., they strived for additional therapeutic assistance, and this proves their desire to compensate for decreasing activity, which they do not want to accept.

Family care and assistance are recognized by modern psychiatry as an important rehabilitation factor; therefore, this aspect was paid much attention during the research. Mentally ill patients were, basically, brought up in single-parent families ( $41.4 \%$ without a father) with a high percentage of careless $(20.5 \%)$ or often conflictive relations $(27.4 \%)$. Besides parents, the patients under study reported on unstable relations with close relatives (41.7\%): in $11.7 \%$ of cases such relations were of a conflictive character, and in $22.2 \%$ of cases were assessed by the patients as "cold." Tension in relations with the family was higher in patients of younger age. A summary of marital status of the patients is given in Fig.2.

Among the respondents, singles dominated; nearly $25 \%$ of the patients were divorced, and only $29.4 \%$ were in a registered marriage. The overwhelming majority $(90.6 \%)$ of single patients, at the moment of the survey, were under the age of 45; these were the people who failed to start a family at the appropriate age. The majority (69.1\%) of divorces occurred within the ages of $21-45$, i.e., the most reproductive period. The majority $(77.7 \%)$ of patients reported that their 
family relations worsened: they lost their interest in a family, and their family members changed their former attitude to the patient, or the marriage broke up.

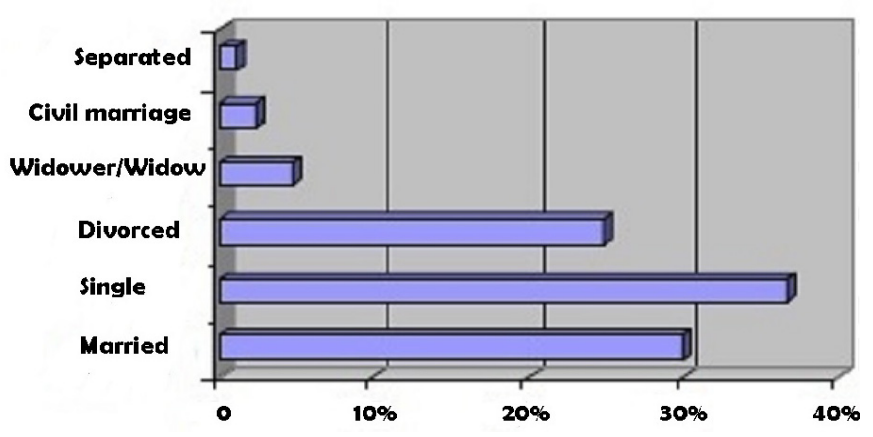

Fig. 2. Marital status of the patients.

Study of intra-familial relations in the patients established that $72.3 \%$ of respondents are not sexually active, and only $7.7 \%$ of the patients are satisfied with their sex lives in general. The younger the patient and the lower his/her satisfaction with the treatment results, the more serious sexual problems he/she faces. It was noted that a considerable part $(42.4 \%)$ of respondents had no children, and only one-third (35.2\%) of the patients had one child; mentally ill women had more children than did mentally ill men.

All of the above underpin the dissatisfaction of many patients with their social role, which is expressed in low selfesteem $(75.41 \%$ of respondents) and, quite frequently, with feelings of self-insignificance and worthlessness $(9.0 \%)$. Approximately a quarter of the patients $(24.3 \%)$ participating in the survey think that the people around (acquaintances, neighbors, etc) them know nothing about their being treated by a psychiatrist. However, it was found that the smaller is the community where a patient resides and the more frequently he/she stayed in a psychiatric facility, the more people know about his/her illness. The fact that those in the immediate social surroundings were aware of MI was negatively perceived by $56.0 \%$ of the respondents: it was unpleasant for them (33.\% of cases), or depressed them ( $45.1 \%$ of cases), or incited them to avoid any communication with their former acquaintances $(17.5 \%)$. Thus, findings of this research allow for emphasizing a special role played by a stigmatization factor in the social functioning of the patients. The stigmatizing effect of MI resulted in $24.3 \%$ of the patients concealing their psychic illness by, $17.5 \%$ avoiding contacts with their acquaintances, $33.9 \%$ experiencing a marked feeling of awkwardness, and some patients striving to receive treatment in any other city or town.

MI brought dramatic changes not only to the life and inner world of a patient but to his/her close people as well, especially if they are always in touch with him/her. Over one-third of relatives (38.8\%) participating in the survey reported on serious restrictions imposed on their professional activity by the illness of their family member: $9.53 \%$ of the respondents lost the possibility of working at all; $12.3 \%$ could not work according to their specialty; and $17.0 \%$ could only have a part-time job. Nearly a half of the relatives $(56.8 \%)$ of the mentally ill consider that illness of their family member brought serious changes to their daily living: $17.4 \%$ of respondents reported that they have to spend a great deal of time with their mentally ill relative as he/she may commit any unpredictable actions; $31.2 \%$ constantly think of a mentally ill relative, which restricts their social opportunities; and 9.0\% cannot leave a patient alone because of his/her dependence on the other person's help. The MI of a close person adversely affected the emotional state of over $30 \%$ of relatives who participated in the survey (36.2\%).

Survey findings showed that the fact of MI, beside its doubtless adverse effects, incited the relatives of mentally ill patients to revise their attitude to the surrounding people and to evaluate their lives through the lens of psychic sufferings experienced by their family member. Over a half of the respondents $(52.7 \%)$ stated that their relative's illness taught them to be kinder to other people: $22.9 \%$ of them developed better understanding of other peoples' grief; $20.1 \%$ became more tolerant of drawbacks of people around them.

The survey showed that the relatives of mentally ill patients need additional information about psychic disorders. A significant number of respondents (73.8\%) was not satisfied with the information obtained from a psychiatrist on the illness of their relative and methods of his/her treatment. Moreover, the respondents $(46.3 \%)$ did not know where they could get any additional information about the illness their relative suffers from, about the benefits they are entitled to as a family of a mentally ill patient (33.8\%), and about the most effective medication $(30.0 \%)$. Almost $31.0 \%$ of respondents were not aware of their rights as members of a family of a mentally ill patient, and $17.8 \%$ never thought whether they have such rights. Fifteen percent of respondents stated that the attending doctor seldom asks them about their opinion on the results of their relative's treatment, and $2.8 \%$ stressed that the attending doctor avoids such conversations at all. Thus, $17.7 \%$ of cases were characterized with insufficient communication among a psychiatrist, mentally ill patient and his/her relatives; $43.7 \%$ of respondents had meetings with the attending doctor less than once in two months and, consequently, had no opportunity to clarify promptly any questions they might have.

The social survey allowed for revealing the attitude of the relatives of mentally ill patients to the therapy given. In general, $61.6 \%$ of respondents considered the prescribed treatment to be 'effective'. However, for the majority of respondents $(63.7 \%)$, a main criterion of therapy effectiveness was decreased frequency of stays of the mentally ill patient in a psychiatric facility, and for $22.1 \%$ of respondents - less care for the patient.

Pursuant to the information obtained from the relatives of mentally ill patient, half the patients refused to take their medication It is possible to assume that such cases were characterized not only by the patients' negative attitude to the therapy (well-known fact), but also by insufficient control exercised by the attending relatives over administration of drugs, which was particularly apparent in cases when mentally ill patients live separately.

A range of sociological questions were targeted at finding out the opinion of relatives of mentally ill patients about ways and methods to improve the effectiveness of MI treatment. 
The ranked majority of respondents (33.4\%) considered 'efficacy of medication prescribed' to be a major method to affect a psychic disorder. The necessity of psychological, social and labor rehabilitation was second $(22.5 \%)$; the other $5.03 \%$ of respondents stressed on importance of both drug therapy and social rehabilitation. The respondents $(46.6 \%)$ associated their role in the treatment of their relatives mostly with strict compliance with the psychiatrist's advice. Besides drug therapy, the respondents considered the following to be important methods of assistance to a mentally-ill relative: communication with other people (29.6\% of respondents), employment $(29.6 \%)$ and participation in socio- and psychotherapy $(21.2 \%)$.

\section{Discussion}

Application of psychosocial rehabilitation is currently acknowledged as one of the most effective approaches to treatment of MI [11, 16-18]. The leading place in this direction is occupied by sociomedical studies of mentally ill patients' daily living and the quality of their lives. In this context, the impact made by MI on families and the social environment of the patients is an important but insufficiently investigated aspect. Methods of research focusing on the daily living of the mentally ill increasingly opt for study of the opinions of the patients themselves and representatives of their social environment on the assistance they get $[6,15]$. This focus represents a switching from the paternalistic to the partner model being implemented in psychosocial rehabilitation programs [16].

\section{Conclusion}

In sum, this was the first attempt in Russian psychiatry to conduct a comprehensive sociomedical study among the mentally ill and their immediate social environment. MI was revealed to have a negative impact on all aspects of the patient's daily living. The presence of MI had a significant impact on various aspects of life of the patients' immediate social environment - members of their families and close people - imposing restrictions on their employment and daily activities, which had a negative effect on their emotional state.

\section{References}

1. Mukhametshina ZF. Social functioning and quality of life of patients suffering from schizophrenia (clinical-and social and psychological aspects). Abstract of PhD Thesis. Moscow; 2009.
2. Neznanov NG, Maslovsky SYu, Ivanov MV. The quality of life of patients suffering from schizophrenia in the course of anti-relapsing therapy. Psychiatry and psychopharmacotherapy 2004; 5: 213-215. [Article in Russian].

3. Solokhina TA. Management of psychiatric assistance quality (results of social survey). Psychiatry 2003; 4: 63-70. [Article in Russian].

4. Shmukler AB. Social functioning and the quality of life of the mentally ill. Abstract of PhD Thesis. Moscow; 1999.

5. Limankin OV. The system of psychosocial assistance to the patients enduring long stays in psychiatric hospitals. Abstract of PhD Thesis. Moscow; 2007.

6. Sultanov MGA. The quality of life and social functioning of patients suffering from schizophrenia enduring long stays in hospitals (clinical and social aspects). Abstract of $\mathrm{PhD}$ Thesis. Moscow; 2005.

7. Harvty PD, Strassing M. Predicting the severity of everyday functional disability in people with schizophrenia: cognitive deficits, functional capacity, symptoms, and health status. World Psychiatry 2012; 11(2):73-9.

8. McClure MM, Bowie CR, Patterson TL, Heaton RK, Weaver C, Anderson H, et al. Correlations of functional capacity and neuropsychological performance in older patients with schizophrenia: evidence for specificity of relationships? Schizophr Res 2007; 89(1-3):330-8.

9. Mikhailova I.I. Self-stigmatization of the mentally ill. Abstract of PhD Thesis. Moscow; 2005.

10. Yastrebov VS, Mikhailova II. The problem of stigma in Russian psychiatry. Psychic Health 2006; 1:61-66. [Article in Russian].

11. Gurovich IYa, Shmukler AB, Storozhakova YaA. Psychosocial therapy and psychosocial rehabilitation in psychiatry. M: Medpraktika; 2004; [Monograph in Russian].

12. Finzen A. Psychosis and stigma. Translated from German. Moscow: Aleteya; 2001.

13. Petrov D.A. The role of family in treatment and rehabilitation of the persons with psychic disorders (comprehensive sociomedical clinical and psychiatric research). PhD Thesis. Moscow; 2012.

14. Kabanov MM. Psychosocial rehabilitation and social psychiatry. Saint-Petersburg; 1998. [Monograph in Russian].

15. Schaub H, Bungenstock A, Flesser L. Rekfallprophylaxe in der Sozialpsychiatrie. Sozialpsychiatrie Informationen 1996; 26(4):9-15. [Article in German].

16. Jenkins R, McCallock E, Friedly L, Parker K. Issues of the national policy development in the sphere of psychical health. Translated from English to Russian. M: Medpraktika; 2005.

17. Nekrasov M.A. Scientific grounds to improve operation by regional mental health service. PhD Thesis. Moscow; 2008. 18. European declaration on mental health care. Materials of research-to practice conference. Moscow: V.P. Serbsky State Scientific Centre of Social and Forensic Psychiatry; 2006:76-100. 